\title{
PENGARUH BAURAN PROMOSI TERHADAP MINAT BELI DENGAN MEDIASI BRAND IMAGE
}

\author{
Kevin Tan \\ Universitas Ciputra \\ ktan01@alumni.ciputra.ac.id \\ Christina Whidya Utami \\ Universitas Ciputra \\ whidyautami@ciputra.ac.id \\ Deandra Vidyanata \\ Universitas Ciputra \\ deandra.vidyanata@ciputra.ac.id
}

\begin{abstract}
The economic growth of the food and beverage industry in East Java keeps on increasing. In 2018, Cikake was established in Surabaya, offering rice-bowl as its main product. Since 2019 Cikake has had its first outlet at a food court called Foodland Pandaan, in Pandaan, East Java. Cikake has a commitment in which every two years will open several offline stores or outlets starting from several cities around Surabaya. During two years running, Cikake's sale turnover has always fluctuated, which has drives Cikake to do promotional activities to improve Cikake's brand image and purchase intention of Cikake consumer. This research aims to determine the effect of promotional mix on purchase intention, the effect of promotional mix on brand image, the effect of brand image on purchase intention, and the effect of promotional mix on purchase intention by mediating brand image. This type of research is quantitative. The population in this research is people who have an interest in Cikake product. The sample consists of 190 respondents using the purposive sampling technique. Data analysis in the research uses Partial Least Square with SmartPLS 3.0 program to calculate data. This research indicates that brand image significantly mediates the effect of promotional mix on purchase intention. Likewise, the promotional mix significantly affects brand image. Also, promotional mix and brand image significantly affect purchase intention.
\end{abstract}

Keywords: brand image; promotional mix; purchase intention

\section{PENDAHULUAN}

Pertumbuhan ekonomi di provinsi Jawa Timur, khususnya pada subsektor industri makanan dan minuman mengalami peningkatan setiap tahunnya. Semakin banyaknya pelaku usaha pada industri makanan dan minuman, menuntut setiap pelaku usaha untuk melakukan kegiatan promosi dalam upaya memberitahukan dan menawarkan produk atau jasa agar dapat menarik calon konsumen untuk membeli (Ariyanto et al., 2020).

Berdasarkan hasil wawancara, Cikake merupakan bisnis yang bergerak pada industri makanan dan minuman, didirikan pada tahun 2018 di Surabaya. Awalnya produk Cikake berupa cake asin, namun seiring dengan perkembangan Cikake membuat produk berupa rice bowl. Pada tahun 2019 Cikake memiliki offline store pertama di pujasera yang bernama Foodland Pandaan, di kota Pandaan, Jawa Timur. Cikake memiliki komitmen di mana setiap 1-2 tahun akan membuka beberapa offline store dimulai dari kota-kota di sekitar Surabaya. Selama dua tahun berjalan, omzet penjualan Cikake mengalami fluktuasi yang mendorong Cikake untuk melakukan kegiatan promosi sebagai pertimbangan ketika membuka offline store selanjutnya. Menurut Sari et al. (2018), penjual menyampaikan pesan atau informasi yang sebagian merupakan brand saat melakukan kegiatan promosi. Kemudian, ketika pesan atau informasi tersebut diterima oleh calon konsumen, akan memengaruhi sikap dan tindakan dalam mengambil keputusan (minat beli). Karena promosi merupakan penyampaian informasi dari penjual kepada pembeli untuk memengaruhi sikap dan tingkah laku dalam rangka menciptakan pertukaran. 
Kevin Tan, et al. Pengaruh Bauran Promosi terhadap Minat Beli dengan Mediasi Brand Image.

Elemen pada bauran promosi merupakan alat-alat yang dapat digunakan untuk melakukan kegiatan promosi. Elemen-elemen pada bauran promosi terdiri dari: advertising, sales promotion, event and experiences, public relation and publicity, social media marketing, mobile marketing, direct and database marketing, personal selling (Kotler \& Keller, 2015). Dalam pelaksanaannya Cikake telah melakukan enam dari total delapan elemen pada bauran promosi yaitu; advertising, sales promotion, Event and experiences, social media marketing, direct marketing dan personal selling. Fokus bauran promosi penelitian ini adalah pada advertising, sales promotion, social media marketing, dan personal selling. Karena pada elemen event and experiences dan direct marketing Cikake telah memiliki offline store, sehingga Cikake tidak lagi melakukan kegiatan promosi pada elemen tersebut.

Cikake memiliki komitmen untuk membuka cabang outlet baru setiap 1-2 tahun, maka penentuan promosi yang tepat sangat dibutuhkan guna memengaruhi minat beli (Prayogi \& Santosa, 2019; Putri, 2018). Minat beli berhubungan langsung dengan keputusan pembelian suatu produk, yang pada akhirnya akan berdampak pada tinggi rendahnya penjualan suatu produk tersebut (Arifin \& Fachrodji, 2015). Di lain sisi, Usman \& Dyanti (2018) menyatakan variabel promosi berdampak negatif terhadap minat beli. Hal ini menunjukkan bahwa terdapat beberapa perbedaan pada hasil penelitian sebelumnya. Oleh karena itu, pada penelitian ini ditambahkan variabel mediasi.

Minat beli ialah rencana sadar individu melakukan upaya untuk membeli suatu produk dengan brand tertentu (Spears \& Singh, 2004). Persepsi dan kepercayaan oleh konsumen sebagai gambaran dari asosiasi yang terdapat dalam memori konsumen disebut brand image (Nurhayati, 2017). Sehingga baik tidaknya persepsi masyarakat terhadap suatu brand bergantung dari pengalaman atau informasi yang diperoleh, jika menginformasikan brand image yang positif maka pandangan terhadap brand tersebut akan menjadi positif (Arifin \& Fachrodji, 2015). Konsumen yang telah memiliki sikap positif terhadap suatu produk atau brand, akan menimbulkan minat pembelian terhadap produk atau brand tersebut (Nulufi \& Murwatiningsih, 2015). Berdasarkan uraian di atas, tujuan penelitian ini untuk mengetahui pengaruh bauran promosi terhadap minat beli, pengaruh bauran promosi terhadap brand image, pengaruh brand image terhadap minat beli, dan pengaruh bauran promosi terhadap minat beli dengan mediasi brand image. Hasil penelitian ini diharapkan dapat membantu dalam meningkatkan minat beli pada Cikake.

\section{KAJIAN PUSTAKA DAN PENGEMBANGAN HIPOTESIS}

\section{Bauran Promosi}

Bauran promosi merupakan campuran spesifik dari alat-alat promosi yang digunakan perusahaan untuk secara persuasif mengkomunikasikan nilai pelanggan dan membangun hubungan pelanggan (Kotler dan Amstrong, 2016). Menurut Hurriyati (2011), bauran promosi adalah perbedaan bentukbentuk promosi berdasarkan tugas khususnya, tetapi memiliki fungsi dan tujuan yang sama. Alida (2012) mendefinisikan bauran promosi sebagai penggunaan sarana dalam membawa pelanggan dari keadaan ketidaksadaran relatif terhadap keadaan aktif mengadopsi produk. Untuk bisa berkomunikasi secara efektif, perusahaan merancang program-program promosinya dengan menarik sehingga mampu menarik minat beli konsumen (Hizkia et al., 2014). Bauran promosi menurut Kotler \& Keller (2015) dibagi menjadi delapan elemen dalam promotion mix, sebagai berikut: advertising, sales promotion, event and experiences, public relation and publicity, social media marketing, mobile marketing, direct and database marketing, personal selling.

\section{Minat Beli}

Liu \& Chen (2006) menyebutkan bahwa minat beli adalah tindakan pribadi dengan tendensi yang relatif terhadap brand tertentu. Minat beli juga dipengaruhi beberapa faktor, seperti faktor psikis yang merupakan faktor pendorong yang berasal dari dalam diri konsumen yaitu motivasi, persepsi, pengetahuan dan sikap (Madiawati \& Pradana, 2016).

\section{Brand Image}

Supangkat \& Supriyatin (2017) menyatakan brand image adalah persepsi seseorang terkait nilai-nilai 
yang terkandung dalam sebuah brand. Menurut Ratri (2007), brand image merupakan asosiasi dari semua informasi yang tersedia mengenai produk, jasa dan perusahaan brand yang dimaksud. Informasi ini didapat melalui dua cara, yakni melalui pengalaman konsumen dan persepsi yang dibentuk oleh perusahaan dari brand tersebut melalui berbagai macam bentuk komunikasi. Brand image yang baik adalah ketika perusahaan dapat memberikan pelayanan terbaik kepada konsumen, brand yang terkenal dan memiliki reputasi baik (Fianto et al., 2014).

\section{Pengaruh Antar Variabel}

Bauran promosi memiliki definisi yaitu, campuran spesifik dari alat-alat promosi yang digunakan perusahaan untuk secara persuasif mengkomunikasikan nilai pelanggan dan membangun hubungan pelanggan (Kotler \& Amstrong, 2016). Oleh karena itu, ketika perusahaan mampu merancang program-program promosinya dengan menarik, maka akan dapat memengaruhi minat beli konsumen (Hizkia et al., 2014). Putri (2018); Khairani \& Lubis (2018); Romadhona et al. (2018); Tantono (2018) mengungkapkan, bauran promosi berpengaruh secara signifikan terhadap minat beli.

\section{H1: Bauran promosi berpengaruh secara signifikan terhadap minat beli}

Bauran promosi sendiri merupakan perbedaan bentuk-bentuk promosi berdasarkan tugas khususnya, tetapi memiliki fungsi dan tujuan yang sama (Hurriyati, 2011). Oleh karena itu, ketika melakukan kegiatan promosi, pesan dan informasi yang disampaikan dari penjual kepada pembeli sebagian merupakan brand (Sari et al., 2018). Sehingga secara tidak langsung kegiatan promosi yang dilakukan akan berpengaruh pada brand image yang dipromosikan. Sari et al. (2018), Rastini \& Nurcaya (2018) memaparkan, terdapat pengaruh yang signifikan antara bauran promosi terhadap brand image.

H2: Bauran promosi berpengaruh secara signifikan terhadap brand image Cikake.

Brand image adalah persepsi seseorang terkait nilai-nilai yang terkandung dalam sebuah brand (Supangkat \& Supriyatin, 2017). Persepsi yang dibentuk didapat melalui dua cara, melalui pengalaman konsumen dan persepsi yang dibentuk oleh perusahaan dari brand tersebut menggunakan berbagai macam bentuk komunikasi (Ratri, 2007). Sehingga minat beli dipengaruhi oleh brand image karena, minat beli merupakan tindakan pribadi dengan tendensi yang relatif terhadap brand tertentu (Liu \& Chen, 2006). Andiyanto \& Fauziah (2019) mengemukakan, brand image berpengaruh secara signifikan terhadap minat beli.

H3: Brand image berpengaruh secara signifikan terhadap minat beli Cikake.

Bauran promosi merupakan campuran spesifik dari alat-alat promosi yang digunakan perusahaan untuk secara persuasif mengkomunikasikan nilai pelanggan dan membangun hubungan pelanggan (Kotler \& Amstrong, 2016). Setelah konsumen terpersuasif maka akan melakukan tindakan pribadi dengan tendensi yang relatif terhadap brand tertentu yang disebut dengan minat beli (Liu \& Chen, 2006). Putri (2018); Khairani \& Lubis (2018); Romadhona et al. (2018); Tantono (2018) menjabarkan, bauran promosi berpengaruh secara signifikan terhadap minat beli. Selain itu, Sari et al. (2018); Rastini \& Nurcaya (2018) menunjukkan adanya pengaruh yang signifikan antara bauran promosi terhadap brand image.

H4: Brand image memediasi pengaruh bauran promosi terhadap minat beli Cikake secara signifikan.

\section{METODE PENELITIAN}

Metode penelitian yang digunakan adalah metode kuantitatif. Populasi pada penelitian ini bersifat tidak terbatas (infinite) dan merupakan seluruh konsumen yang memiliki minat pada produk Cikake. 
Kevin Tan, et al. Pengaruh Bauran Promosi terhadap Minat Beli dengan Mediasi Brand Image.

Sampel penelitian sebanyak 190 responden, menggunakan metode non probability sampling dan teknik purposive sampling dengan kriteria konsumen yang memiliki minat pada produk Cikake dan usia 17-40 tahun. Jenis data yang digunakan pada penelitian ini adalah data primer dan data sekunder.

Data primer diambil dari kuesioner menggunakan media Google form. Kuesioner menggunakan skala likert dengan pilihan jawaban dan skor, yaitu: Sangat Tidak Setuju (STS) dengan nilai skor 1, Tidak Setuju (TS) dengan nilai skor 2, Cukup Setuju (CS) dengan nilai skor 3, Setuju (S) dengan nilai skor 4, dan Sangat Setuju (SS) dengan nilai skor 5.

Data sekunder diperoleh dari catatan-catatan maupun dokumen bisnis, buku, makalah, laporan, penelitian terdahulu, statistika, dan literatur lainnya. Teknik analisis data menggunakan Structural Equation Model (SEM) berbasis Partial Least Square (PLS), dengan software SmartPLS 3.0. Menurut Ghozali (2018) langkah-langkah yang perlu dilakukan dalam penelitian ini dimulai dengan merancang model pengukuran (outer model) setelah itu merancang model struktural (inner model).

\section{HASIL DAN PEMBAHASAN}

\section{Karakteristik Responden}

Karakteristik responden meliputi klasifikasi jenis kelamin, usia, pekerjaan, dan penghasilan. Jumlah responden menurut klasifikasi jenis kelamin yaitu laki-laki (50,5\%), perempuan (49,5\%). Menurut klasifikasi usianya mayoritas responden berusia 17-25 tahun (90,5\%), 26-35 tahun (8,5\%), dan usia> 35 tahun (1\%). Pekerjaan responden didominasi mahasiswa (71\%), karyawan $(11,5 \%)$, wirausaha $(14 \%)$, dan lain-lain (3,5\%). Responden menurut jumlah penghasilan perbulan< Rp5.000.000 (71\%), Rp5.000.000-Rp10.000.000 (24\%), dan penghasilan perbulan> Rp10.000.000 (5\%).

\section{Uji Validitas dan Uji Reliabilitas}

Tabel 1.

\section{UJI VALIDITAS}

\begin{tabular}{|c|c|c|c|c|c|c|}
\hline \multirow[b]{2}{*}{ Variabel } & \multirow[b]{2}{*}{ Indikator } & \multirow{2}{*}{$\begin{array}{c}\text { Loading } \\
\text { Factor }\end{array}$} & \multirow{2}{*}{$\begin{array}{c}\text { Average Variance } \\
\text { Extracted (AVE) }\end{array}$} & \multicolumn{3}{|c|}{ Cross Loading } \\
\hline & & & & $\begin{array}{l}\text { Bauran } \\
\text { Promosi }\end{array}$ & $\begin{array}{c}\text { Minat } \\
\text { Beli }\end{array}$ & $\begin{array}{l}\text { Brand } \\
\text { Image }\end{array}$ \\
\hline \multirow{10}{*}{$\begin{array}{l}\text { Bauran } \\
\text { Promosi } \\
\text { (X) }\end{array}$} & X.1.3 & 0,764 & \multirow{10}{*}{0,609} & 0,728 & 0,445 & 0,534 \\
\hline & X.2.1 & 0,766 & & 0,776 & 0,456 & 0,544 \\
\hline & X.2.2 & 0,791 & & 0,814 & 0,448 & 0,552 \\
\hline & X.2.3 & 0,761 & & 0,777 & 0,552 & 0,525 \\
\hline & X.3.1 & 0,766 & & 0,757 & 0,558 & 0,566 \\
\hline & X.3.2 & 0,796 & & 0,790 & 0,520 & 0,544 \\
\hline & X.3.3 & 0,740 & & 0,744 & 0,479 & 0,592 \\
\hline & X.4.1 & 0,718 & & 0,750 & 0,469 & 0,596 \\
\hline & X.4.2 & 0,812 & & 0,835 & 0,508 & 0,545 \\
\hline & X.4.3 & 0,803 & & 0,825 & 0,527 & 0,549 \\
\hline \multirow{4}{*}{$\begin{array}{l}\text { Minat Beli } \\
\text { (Y) }\end{array}$} & Y.1 & 0,764 & \multirow{4}{*}{0,662} & 0,465 & 0,767 & 0,468 \\
\hline & Y.2 & 0,849 & & 0,564 & 0,851 & 0,565 \\
\hline & Y.3 & 0,843 & & 0,576 & 0,840 & 0,564 \\
\hline & Y.4 & 0,796 & & 0,460 & 0,794 & 0,521 \\
\hline \multirow{3}{*}{$\begin{array}{l}\text { Brand Image } \\
\text { (M) }\end{array}$} & M.1 & 0,816 & \multirow{3}{*}{0,644} & 0,625 & 0,638 & 0,804 \\
\hline & M.2 & 0,844 & & 0,620 & 0,496 & 0,850 \\
\hline & M.3 & 0,741 & & 0,433 & 0,398 & 0,750 \\
\hline
\end{tabular}

Sumber: Data diolah dari SmartPLS 3.0 2020 
Tabel 1 mengindikasikan terdapat satu indikator pada variabel bauran promosi yang memiliki nilai loading factor $<0,70$, yaitu indikator X.1.1. Sehingga harus dihilangkan karena tidak dapat mewakili atau menggambarkan variabel latennya. Kemudian, indikator X.1.2 diuji kembali dengan menghilangkan indikator X.1.1. Nilai loading factor indikator X.1.2 yang sebelumnya sebesar 0,724 menjadi 0,690. Maka dari itu indikator X.1.2 juga dihilangkan karena tidak dapat mewakili atau menggambarkan variabel latennya. Setelah menghilangkan dua indikator pada variabel bauran promosi, jumlah total indikator menjadi 17 indikator, di mana semula berjumlah 19 indikator. Seluruh indikator dalam penelitian ini valid, sehingga dapat mewakili dan menggambarkan variabel-variabel latennya.

Nilai AVE pada variabel bauran promosi sebesar 0,609, variabel minat beli sebesar 0,662, dan variabel brand image sebesar 0,644. Semua variabel memiliki nilai AVE di atas 0,5. Hal ini menunjukkan bahwa indikator pada masing-masing variabel telah mewakili dan menggambarkan variabel latennya.

Hasil cross loading dari seluruh indikator variabel memiliki nilai> 0,70. Selain itu nilai cross loading pada variabel yang sesuai memiliki nilai yang lebih besar dibandingkan dengan nilai cross loading variabel lain. Hal ini mengindikasikan bahwa setiap indikator memiliki sifat satu pengertian yang sama dengan variabel latennya atau biasa disebut sifat undimensional.

Tabel 2.

\section{UJI RELIABILITAS}

\begin{tabular}{cccc}
\hline Variabel & Cronbach's Alpha & Composite Reliability & Nilai R-square \\
\hline Bauran Promosi & 0,928 & 0,940 & - \\
Minat Beli & 0,830 & 0,887 & 0,487 \\
Brand Image & 0,729 & 0,844 & 0,507 \\
\hline
\end{tabular}

Sumber: Data diolah dari SmartPLS 3.02020

Tabel 2 menampilkan nilai cronbach's alpha pada variabel bauran promosi, variabel minat beli, dan variabel brand image, yakni sebesar 0.928, 0.830, dan 0.729. Ketiga variabel tersebut telah memiliki nilai cronbach's alpha di atas 0,7 . Sehingga, seluruh variabel pada penelitian ini reliabel. Nilai composite reliability. Pada variabel bauran promosi sebesar 0,940, variabel minat beli sebesar 0,887, dan variabel brand image sebesar 0,844. Ketiga variabel memiliki nilai composite reliability di atas 0,7. Artinya, indikator-indikator pada penelitian reliabel. Sehingga meskipun dilakukan pengukuran secara berulang, tetap akan mendapatkan hasil yang akurat.

\section{Evaluasi Model Struktural (Inner Model)}

Tabel 2 memperlihatkan nilai R-square variabel minat beli sebesar 0,487, yang berarti variasi perubahan variabel minat beli yang dapat dijelaskan oleh variabel bauran promosi sebesar 48,7\%. Nilai R-square pada variabel brand image sebesar 0,507. Artinya variasi perubahan variabel brand image yang dapat dijelaskan oleh variabel bauran promosi adalah sebesar 50,7\%.

Tabel 3.

UJI PATH COEFFICIENTS DAN INDIRECT EFFECTS

\begin{tabular}{cccc}
\hline Variabel & $\begin{array}{c}\text { T Statistics } \\
(\mid \mathbf{O} / \text { STDEV }])\end{array}$ & T-tabel & P Values \\
\hline Bauran Promosi $\rightarrow$ Minat Beli & 4,077 & 1,96 & 0,000 \\
Bauran Promosi $\rightarrow$ Brand Image & 18,217 & 1,96 & 0,000 \\
Brand Image $\rightarrow$ Minat Beli & 4,583 & 1,96 & 0,000 \\
Bauran Promosi $\rightarrow$ Brand Image $\rightarrow$ Minat Beli & 4,575 & 1,96 & 0,000 \\
\hline Bum
\end{tabular}

Sumber: Data diolah dari SmartPLS 3.0 2020 
Kevin Tan, et al. Pengaruh Bauran Promosi terhadap Minat Beli dengan Mediasi Brand Image.

\section{Uji Hipotesis Langsung (Path Coefficients)}

Nilai T-statistic pada Tabel 3 menampilkan hubungan antar variabel pertama yaitu bauran promosi terhadap minat beli sebesar 4,077. Hubungan antar variabel kedua bauran promosi terhadap minat beli memiliki nilai T-statistic terbesar, yakni 18,217. Hubungan antar variabel ketiga brand image terhadap minat beli memiliki nilai T-statistic sebesar 4,583. Ketiga hubungan antar variabel memiliki nilai T-statistic di atas 1,96, hal ini berarti semua hubungan antar variabel memiliki pengaruh positif dan signifikan.

\section{Uji Hipotesis Tidak Langsung (Indirect Effects)}

Tabel 3 menunjukkan nilai T-statistic hubungan antar variabel brand image memediasi pengaruh bauran promosi terhadap minat beli sebesar 4,575. Nilai T-statistic pada antar variabel ini lebih besar dari nilai T-statistic pada antar variabel bauran promosi terhadap minat beli dan nilai T-statistic pada penelitian ini lebih besar dari nilai T-tabel yang menjadi syarat agar hipotesis dapat diterima, yakni 1,96. Hal ini menunjukkan bahwa variabel brand image berhasil berperan sebagai mediasi dalam pengaruh bauran promosi terhadap minat beli pada penelitian ini.

\section{Pengaruh Bauran Promosi terhadap Minat Beli}

Bauran promosi memiliki pengaruh positif dan signifikan terhadap minat beli pada Cikake. Hal ini mendukung H1 yang sejalan dengan Khairani \& Lubis (2018); Romadhona et al. (2018); Tantono (2018), yaitu bauran promosi memiliki pengaruh signifikan terhadap minat beli. Putri (2018) memaparkan hasil yang serupa, bahwa komponen-komponen pada bauran promosi memiliki dampak terhadap minat beli. Sesuai dengan Hizkia et al. (2014), jika perusahaan mampu merancang programprogram promosinya dengan menarik, maka akan dapat memengaruhi minat beli konsumen.

Menurut Kemp (2021) media sosial merupakan sarana kegiatan promosi yang memiliki daya tarik paling tinggi saat ini dengan lebih dari $53 \%$ penduduk dunia sebagai pengguna. Berdasarkan pengamatan, sebagian besar kegiatan promosi yang telah dilakukan Cikake pada elemen advertising dan sales promotion telah menggunakan sarana media sosial dalam pelaksanaannya. Pada elemen advertising Cikake menampilkan brosur digital pada media sosial, dan pada elemen sales promotion menggunakan media sosial untuk menyampaikan promosi penjualan yang dilakukan antara lain potongan harga (discount) dan kartu member. Hal ini sesuai dengan target segmen pada perusahaan Cikake yang tertuju pada generasi milenial.

\section{Pengaruh Bauran Promosi terhadap Brand Image}

Bauran promosi berpengaruh secara signifikan terhadap brand image Cikake. Hasil tersebut mendukung H2 yang sesuai dengan Rastini \& Nurcaya (2018); Sari et al. (2018), bahwa terdapat pengaruh yang signifikan antara bauran promosi terhadap brand image. Hal ini dapat terjadi karena kegiatan promosi merupakan salah satu bentuk komunikasi pemasaran yang dilakukan oleh perusahaan dalam rangka proses membangun dan meningkatkan brand image, kegiatan ini biasanya disebut branding (Rastini \& Nurcaya, 2018; Rachman, 2015). Ketika melakukan kegiatan promosi, pesan dan informasi yang disampaikan dari penjual kepada pembeli sebagian merupakan brand. Hal ini disebabkan kegiatan promosi yang dilakukan mempunyai target audience yang luas, sehingga pesan yang ingin disampaikan tentang brand image dapat tersampaikan (Sari et al., 2018).

\section{Pengaruh Brand Image terhadap Minat Beli}

Brand image berpengaruh positif dan signifikan terhadap minat beli pada Cikake. Hasil tersebut sejalan dengan H3 yang didukung oleh Maghfiroh \& Zainul (2016); Priyono et al. (2016); Andiyanto \& Fauziah (2019) yaitu brand image berpengaruh positif dan signifikan pada minat beli karena semakin baik dan besarnya brand image suatu produk maka minat beli konsumen juga akan semakin meningkat. Hal ini dapat terjadi karena minat beli merupakan tindakan pribadi dengan tendensi yang relatif terhadap brand tertentu (Liu \& Chen, 2006).

\section{Pengaruh Bauran Promosi terhadap Minat Beli dengan Brand Image sebagai Mediasi}

Brand image berhasil memediasi antara pengaruh bauran promosi terhadap minat beli pada Cikake. 
Hal ini mendukung $\mathrm{H} 4$, bahwa brand image memediasi pengaruh bauran promosi terhadap minat beli Cikake secara signifikan. Pengaruh brand image sebagai variabel mediasi cukup besar jika dibandingkan dengan uji langsung pada pengaruh bauran promosi dan minat beli.

Bauran promosi dalam perannya sebagai komunikasi pemasaran mempunyai peran dalam membangun brand image (Rachman, 2015). Brand image merepresentasikan semua informasi yang tersedia mengenai produk, jasa dan perusahaan dari brand tersebut (Ratri, 2007). Informasi ini didapat melalui dua cara, yakni melalui pengalaman konsumen dan persepsi yang dibentuk oleh perusahaan melalui berbagai macam bentuk komunikasi. Hal ini terjadi karena awalnya dimulai dari kegiatan promosi yang dilakukan oleh perusahaan, kegiatan promosi meliputi menyampaikan informasiinformasi termasuk brand kepada konsumen (Sari et al., 2018). Brand yang diterima oleh konsumen selanjutnya akan diproses oleh konsumen hingga membentuk suatu persepsi di benak konsumen, persepsi brand image inilah yang selanjutnya akan memengaruhi tindakan pribadi konsumen terhadap brand tersebut (minat beli).

\section{Implikasi Manajerial}

Berdasarkan penelitian yang telah dilakukan, didapatkan beberapa hasil yang dapat diterapkan pada perusahaan Cikake maupun untuk para perusahaan sejenis lainnya. Berikut adalah implikasi manajerial sebagai pertimbangan untuk membuat perbaikan pada Cikake atau perusahaan sejenis.

Pertama, berdasarkan variabel bauran promosi. Hasil dari penelitian ini variabel bauran promosi berpengaruh signifikan terhadap minat beli dan juga brand image. Kegiatan promosi yang selama ini dilakukan Cikake sudah cukup banyak. Hanya saja Cikake kurang fokus pada setiap kegiatan promosi yang dilakukan. Implikasi manajerial yang dapat dipertimbangkan untuk diterapkan adalah menentukan elemen yang tepat pada kegiatan promosi. Hasil observasi menunjukkan Cikake fokus pada elemen sales promotion, social media marketing, dan personal selling. Oleh karena itu kegiatan promosi yang sebaiknya dilakukan antara lain, endorsement selebgram, promosi pada event khusus, bundling menu dengan outlet sekitar, serta potongan harga yang lebih menarik. Setiap elemen pada bauran promosi yang dipilih harus memiliki beberapa strategi promosi. Karena, promosi yang hanya fokus pada satu strategi saja menyebabkan tidak efisiennya kegiatan promosi tersebut (Rohaeni, 2016).

Kedua, berdasarkan variabel brand image. Hasil dari penelitian ini variabel brand image berpengaruh terhadap minat beli dan juga memediasi pengaruh bauran promosi terhadap minat beli. Maka, implikasi manajerial yang dapat dipertimbangkan untuk diterapkan adalah memastikan konten dari setiap kegiatan promosi juga menyampaikan informasi tentang brand Cikake sehingga kegiatan promosi yang intens dan masif akan meningkatkan brand image yang positif dan berpengaruh terhadap minat beli. Selain itu, brand image yang dikenal luas dapat memengaruhi sikap dan preferensi, sehingga dapat memengaruhi minat beli.

Terakhir, persepsi konsumen yang sudah ada mengenai brand image dapat dimanfaatkan untuk menciptakan inovasi baru pada produk Cikake guna meningkatkan minat beli. Hal ini dapat menjadi pertimbangan untuk Cikake dan perusahaan sejenis yang ingin membentuk brand image dengan melakukan kegiatan promosi agar tercapai brand image yang positif sehingga berpengaruh pada minat beli.

\section{KESIMPULAN}

Berdasarkan hasil penelitian, bauran promosi yang terdiri dari advertising, sales promotion, social media marketing, dan personal selling memiliki pengaruh yang signifikan terhadap minat beli pada Cikake, bauran promosi berpengaruh signifikan terhadap brand image Cikake, brand image berpengaruh signifikan terhadap minat beli pada Cikake, dan brand image dapat memediasi pengaruh 
Kevin Tan, et al. Pengaruh Bauran Promosi terhadap Minat Beli dengan Mediasi Brand Image.

bauran promosi terhadap minat beli pada Cikake. Hasil penelitian ini dapat dijadikan sebagai rujukan pada penelitian selanjutnya dan disarankan untuk menambah variabel lain yang tidak terdapat pada penelitian ini.

Penelitian ini memiliki keterbatasan yaitu beberapa jawaban responden memiliki nilai skala yang sama pada seluruh pernyataan, serta penyebaran kuesioner menggunakan QR Code pada outlet Cikake di Foodland Pandaan, menunjukkan feedback yang kurang maksimal. Sebab, keadaan pandemi Covid19 membuat konsumen lebih memilih untuk membeli produk secara online (tanpa harus ke outlet).

\section{DAFTAR PUSTAKA}

Alida, W. (2012). Kajian Bauran Promosi di Perguruan Tinggi "X". Jurnal Liquidity, 1(2), 175-182.

Andiyanto, Ato'illah, M., \& Fauziah, A. (2019). Price and Brand Image Analysis of Interest in Buying Re Madjank Store Brand Product. Progress Conference, 2, 251-254.

Arifin, E., \& Fachrodji, A. (2015). Pengaruh Persepsi Kualitas Produk, Citra Merek dan Promosi Terhadap Minat Beli Konsumen Ban Achilles di Jakarta Selatan. Jurnal MIX, V(1), 124-143.

Ariyanto, A., Nuryani, A., \& Sunarsih. (2020). Pengaruh Store Atmosphere dan Promosi Terhadap Keputusan Pembelian pada Alfamart BSD Tangerang Selatan. Jurnal Ekonomi Efektif, 3(1), 2936.

Fianto, A. A., Hadiwidjojo, D., Aisjah, S., \& Solimun. (2014). The Influence Brand Image on Purchase Behaviour Through Brand Trust. The Journal of Business Management and Strategy, Macrothink Institute, 5(2), 58.

Ghozali, I. (2018). Aplikasi Analisis Multivarate dengan Program IBM SPSS. Edisi Kesembilan. Semarang: Penerbit Universitas Diponegoro.

Hizkia, B. A., Lapian, S. J., \& Mekel, P. A. (2014). Atribut Produk dan Bauran Promosi Pengaruhnya Terhadap Keputusan Pembelian Sepeda Motor Yamaha Mio. Jurnal EMBA, 2(1), 225-230.

Hurriyati, R. (2011). Bauran Pemasaran dan Loyalitas Konsumen. Bandung: Penerbit Alfabeta.

Kemp, S. (2021). Digital 2021: Global Overview Report - DataReportal - Global Digital Insights. Diakses 1 Februari 2021, dari https://datareportal.com/reports/digital-2021-global-overview-report.

Khairani, Z., \& Lubis, N. (2018). Promotion Mix Strategies and Buying Interest of Riau Specific Food Souvenirs. IOP Conf. Series: Earth and Environmental Science, 175, 1-7.

Kotler, P., \& Amstrong, G. (2016). Prinsip-prinsip Pemasaran, Edisi 13, Jilid 1. Jakarta: Erlangga.

Kotler, P., \& Keller, K. L. (2015). Marketing Management (15th ed.). New Jersey: Pearson.

Liu, J., \& Chen, J. (2006). Virtual Experiential Marketing On Online Purchase Intention. In 11th Annual Conference of Asia Pacific Decision Sciences Institute (pp. 325-333). Hongkong; APDSI.

Maghfiroh, A. A., \& Zainul, S. (2016). Pengaruh Citra Merek Terhadap Minat beli dan Keputusan Pembelian (Survei pada Mahasiswa Program Studi Administrasi Bisnis Tahun Angkatan 2013/2014 Fakultas Ilmu Administrasi Universitas Brawijaya Malang Pembeli Indosat). Jurnal Administrasi Bisnis, 40(1), 132-140.

Madiawati, P. N., \& Pradana, M. (2016). Celebrity and Halal Certificates Factor Influence on Customer Buying Interest. Actual Problem of Economics, 3, 109-116. 
Nulufi, K., \& Murwatiningsih. (2015). Minat Beli Sebagai Mediasi Pengaruh Brand Image dan Sikap Konsumen terhadap Keputusan Pembelian Batik di Pekalongan. Management Analysis Journal, 4(2), 129-141.

Nurhayati, S. (2017). Pengaruh Citra Merek, Harga dan Promosi terhadap Keputusan Pembelian Handphone Samsung di Yogyakarta. JBMA, IV(2), 60-69.

Prayogi, S., \& Santosa, A. (2019). The Influence Of product Quality, Price and Promotions On Interest In Buying Sri Sulastri's Batik. e-Jurnal Apresiasi Ekonomi , 7(1), 9-17.

Priyono, E. T., Haryono, \& Maria, M. M. (2016). Analisis Pengaruh Citra Merek, Strategi Promosi, Atribut Produk, Harga terhadap Minat Berkunjung Serta Pengaruhnya terhadap Minat Beli (Studi Empiris Pada Pameran Computer Javamall Semarang). Journal of Management, 2( 2), 122.

Putri, Y. A. (2018). Pengaruh Bauran Promosi dan Gaya Hidup terhadap Minat Beli pada Kedai Kopi Serasi. Jurnal Manajemen Strategi dan Aplikasi Bisnis, 1(2), 137-144.

Rachman, B. J. (2015). Analisis Pengaruh Desain Produk dan Promosi terhadap Kemantapan Keputusan Pembelian Yang Dimediasi oleh Citra Merek. Diponegoro Journal of Management, 4(1), 266-279.

Rastini, N. M., \& Nurcaya, I. N. (2018). Pengaruh Country of Origin Perception, Perceived Quality dan Promotional Mix terhadap Purchase Intention dengan Brand Image Sebagai Variabel Intervening (Studi pada Smartphone Buatan Indonesia). Competence, Journal of Management Student, Vol. 12(1), 36.

Ratri, L. E. (2007). Strategi Memenangkan Persaingan Pasar. Jakarta: Salemba Empat.

Rohaeni, H. (2016). Pernana Promosi Melalui Personal Selling terhadap Volume Penjualan. Ecodemica, IV(2), 223-231.

Romadhona, R. N., Sudapet, N., \& Subagio, H. D. (2018). Influence of Packaging Design, Promotion and Brand Image on Consumer Buying Interest (Study Case of Consumer Glek-Glek Tea Nganjuk). International Journal of Integrated Education, Engineering and Business, 1(2), 6878.

Sari, S. I., Rachma, N., \& Slamet, A. R. (2018). Pengaruh Brand Identity dan Promotion Mix Terhadap Brand Image dengan Brand Awareness Sebagai Variabel Intervening. e-Jurnal Riset Manajemen Prodi Manajemen, 8(4), 107-120.

Spears, N., \& Singh, S. N. (2004). Measuring Attitude Toward The Brand and Purchase Intentions. Journal of Current Issues \& Research in Advertising, 26(2), 53-66.

Supangkat, A. H., \& Supriyatin. (2017). Pengaruh Citra Merek, Kualitas Produk, Harga terhadap Keputusan Pembelian Tas di Intako. Jurnal Ilmu dan Riset Manajemen, 6(9), 1-19.

Tantono, A. A. (2018). Pengaruh Promotion Mix Terhadap Minat Beli Konsumen Strap. PERFORMA: Jurnal Manajemen dan Start-Up Bisnis, 2(6), 815-824.

Usman, O., \& Dyanti, N. (2020). The Influence of Price, Promotion, and Word of Mouth On Buying Interest. SSRN Electronic Journal. https://doi.org/10.2139/ssrn.3638868 